\title{
Aspartoacylase Deficiency in the White Matter of Human Immunodeficiency Virus Encephalitis: Novel Mechanism in Axonal Damage
}

\author{
Sankar Surendran ${ }^{1}$ and Srinivasagam Rajasankar ${ }^{2}$ \\ ${ }^{1}$ Division of GSBS, UNT Health Science Center, Fort Worth, TX 76107, USA \\ ${ }^{2}$ Department of Anatomy, Melmaruvathur Adhiparasakthi Institute of Medical Sciences, Tamil Nadu 603319, India
}

Correspondence should be addressed to Sankar Surendran, sankar_surendran@yahoo.com

Received 23 March 2011; Accepted 7 July 2011

Academic Editor: Wong Kum Thong

Copyright () 2011 S. Surendran and S. Rajasankar. This is an open access article distributed under the Creative Commons Attribution License, which permits unrestricted use, distribution, and reproduction in any medium, provided the original work is properly cited.

\begin{abstract}
Aspartoacylase/aminoacylase II (ASPA/ACY II) is mainly synthesized in oligodendrocytes to contribute in myelin synthesis. Although axonal damage is seen in the brain with human immunodeficiency virus encephalitis (HIVE), ASPA contribution in the pathology is not known. Immunostaining study showed that ASPA protein is reduced in the white matter of patients with HIVE compared to the control. Western blot study further confirmed ASPA deficiency in the HIVE brain compared to the control. This paper suggests that HIVE condition affects ASPA to contribute in myelin loss/axonal damage seen in the disease.
\end{abstract}

\section{Introduction}

Human aspartoacylase/aminoacylase II (ASPA/ACY II; EC no. 3.5.1.15) gene contains five introns and six exons $[1,2]$. Normal level of its substrate, N-acetylaspartic acid (NAA/NA-Asp) is important for the maintenance of healthy neurons. Altered levels of the NAA contribute in disease pathophysiology by inducing oxidative stress and by suppressing potential antioxidants [3-6]. Abnormal level of this pathway contributes in various diseases including Canavan disease [1-4], type 2 diabetes [7], and Parkinson's disease [8]. Aspartoacylase is mainly synthesized in oligodendrocytes to contribute in myelin synthesis $[1,2]$.

Human immunodeficiency virus encephalitis (HIVE) is a demyelinating disease of the central nervous system, caused by the lethal virus [9-11]. Approximately 2.7 million new HIV-1 infections and 2.0 million deaths due to AIDS were reported in 2008 [12, 13]. In North America, the epidemic is expanding in the population among men who have sex with men $[14,15]$. Brain regions affected in the disease include basal ganglia and deep white matter $[16,17]$, and these brain regions are also affected in the brain with Canavan disease $[1,2]$, therefore studying aspartoacylase level in the white matter of the patients with HIVE is important. Thus, the present study was aimed to understand ASPA level in the white matter of patients HIVE.

\section{Materials and Methods}

Six brain samples each from control and HIVE were used. While control brains showed no histologic abnormalities, HIVE brain showed leucoencephalopathy. All the procedures were performed under the regulations of institutional ethical committee and with the Helsinki Declaration of 1975, as revised in 2000 (World Medical Association Declaration of Helsinki 2000). To perform immunostaining, paraffin sections from three each of control and HIVE brain were deparaffinized in xylene, rehydrated in graded ethanol and incubated with ASPA antibody (Santacruz, CA) as followed earlier [18]. The slides were then washed in PBS and incubated with antirabbit conjugated Alexa-fluor 488 (Molecular probes, CA). Sections were photographed as described earlier [18].

To confirm the immunofluorescence findings, western blot was performed using three of each control and HIVE 


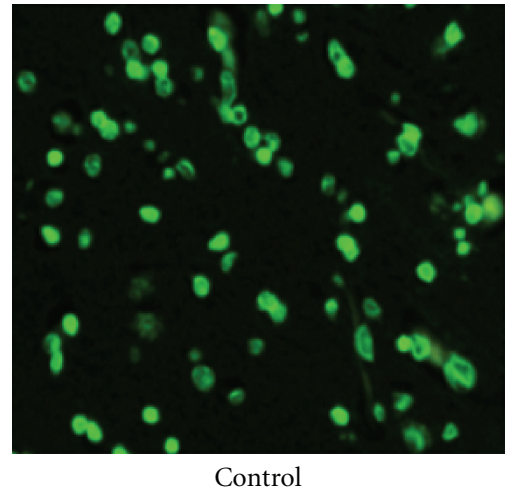

(a)

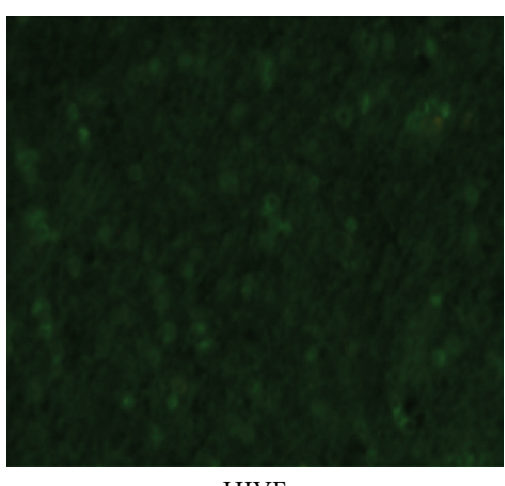

HIVE

(b)

FIGURE 1: Immunofluorescence study of aspartoacylase in the brain of patients with HIVE. Aspartoacylase protein is reduced in the fore brain of HIVE patients compared to the control (magnification, 20x).

brain samples. Three brain samples of each control and HIVE were homogenized in lysis buffer and western blot was performed as followed earlier [19]. Fifteen-microgram protein from control and HIVE brains was loaded onto a $12 \%$ gel and the protein transferred nitrocellulose membrane was blocked with $5 \%$ blocking buffer. Then the membrane was incubated with ASPA antibody (Santa Cruz, CA) $1: 200$ dilution. After washing with PBS, membrane was incubated with anti-rabbit HRP antibody (Invitrogen, CA). The protein band was detected using supersignal west pico chemiluminescent substrate (Fisher scientific, IL) and photographed as described earlier [19]. Density of the bands was also measured as described earlier [19]. Statistical analysis was performed using ANOVA. $P<0.05$ was considered as significant.

\section{Results and Discussion}

Immunostaining of the HIVE brain white matter showed reduced level of ASPA compared to the control (Figure 1). These fluorescent cells were colocalized with oligodendrocyte marker (Data not shown). Western blot study also further confirmed the reduced level of ASPA in HIVE brain compared to the control (Figure 2). Density analysis of the bands showed that two-tailed $P$ value was 0.02 .

HIV has been a devastating disease over decades and white matter degeneration is also reported [20,21], however, ASPA contribution in the white matter degeneration is not known. ASPA is mainly synthesized in oligodendrocytes [1, 2 ] and a reduced level of ASPA impedes myelination and thus leads to axonal damage $[1,2,22,23]$.

Human immunodeficiency virus infection starts from periphery and subsequently enters the central nervous system but neurological symptoms occur years later. Axonal damage is reported in the brain with $\operatorname{HIVE}[24,25]$. Monogene alters other genes expression to contribute in disease pathophysiology [2]. HIV is capable of inserting with genomic DNA [26]. This insertion would impede function of other genes. Thus, deficiency of ASPA in the brain of patients with HIVE observed in the present study suggests

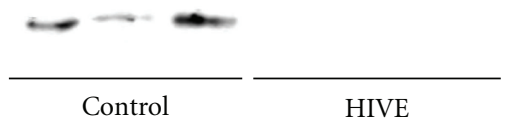

(a)

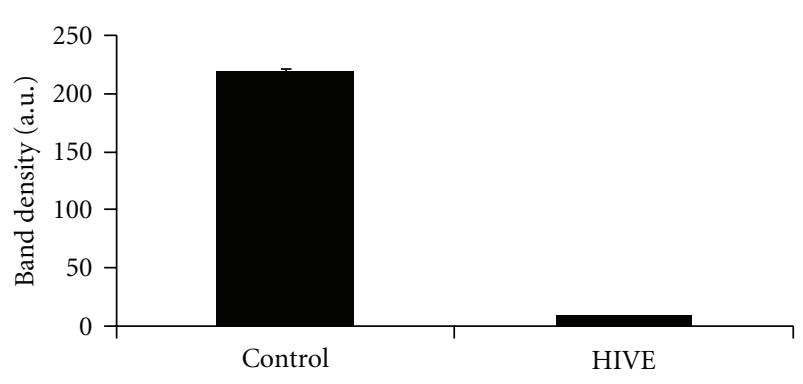

(b)

FIGURE 2: Western blot study of aspartoacylase protein in the brain of patients with HIVE. (a) Aspartoacylase protein was deficient in the brain of patients with HIVE compared to the control. (b) Density analysis of the band showed reduced amount of ASPA protein in the brain with HIVE compared to the control brain. Twotailed $P$ value was 0.02 .

that HIVE condition affects ASPA to contribute in myelin loss and axonal damage seen in the disease.

In conclusion, HIVE condition affects ASPA to contribute in axonal damage seen in the disease.

\section{References}

[1] S. Surendran, N. Kaya, and P. Ozand, "Canavan disease: molecular pathology, phenotype and therapeutic approaches," in Neurochemistry of Metabolic Diseases: Lysosomal Storage Diseases, Phenylketonuria and Canavan Disease, S. Surendran, Ed., chapter 13, Nova Science Publishers, Huntington, NY, USA, 2011.

[2] S. Surendran and G. Kumaresan, "Neurochemical changes and therapeutic approaches in Canavan disease," in Neurochemistry of Metabolic Diseases: Lysosomal Storage Diseases, 
Phenylketonuria and Canavan Disease, S. Surendran, Ed., pp. 119-132, Transworld Research Network, Trivandrum, India, 2007.

[3] S. Surendran and M. Bhatnagar, "Upregulation of N-acetylaspartic acid induces oxidative stress to contribute in disease pathophysiology," International Journal of Neuroscience, vol. 121, no. 6, pp. 305-309, 2011.

[4] S. Surendran, "Upregulation of $\mathrm{N}$-acetylaspartic acid resulting nitric oxide toxicity induces aspartoacylase mutations and protein interaction to cause pathophysiology seen in Canavan disease," Medical Hypotheses, vol. 75, no. 6, pp. 533-534, 2010.

[5] S. Surendran, "N-Acetyl aspartate induces nitric oxide to result neurodegeneration in Canavan disease," Bioscience Hypotheses, vol. 1, no. 4, pp. 228-229, 2008.

[6] S. Surendran, "N-acetylaspartic acid monitors oxidative stress. Experimental and clinical sciences," International Online Journal for Advances in Sciences, vol. 10, pp. 52-58, 2011.

[7] S. Surendran, R. Matalon, and S. K. Tyring, "Upregulation of aspartoacylase activity in the duodenum of obesity induced diabetes mouse: implications on diabetic neuropathy," Biochemical and Biophysical Research Communications, vol. 345, no. 3, pp. 973-975, 2006.

[8] S. Surendran and S. Rajasankar, "Parkinson's disease: oxidative stress and therapeutic approaches," Neurological Sciences, vol. 31, no. 5, pp. 531-540, 2010.

[9] P. Cinque, I. J. Koralnik, and D. B. Clifford, "The evolving face of human immunodeficiency virus-related progressive multifocal leukoencephalopathy: defining a consensus terminology," Journal of NeuroVirology, vol. 9, 1, pp. 88-92, 2003.

[10] M. K. White and K. Khalili, "Pathogenesis of progressive multifocal leukoencephalopathy-revisited," Journal of Infectious Diseases, vol. 203, no. 5, pp. 578-586, 2011.

[11] E. Tavazzi, V. Bargiggia, A. Pichiecchio et al., "HIV-related acute inflammatory leukoencephalopathy of undetermined origin: review of the literature," International Journal of Immunopathology and Pharmacology, vol. 23, no. 3, pp. 693-700, 2010.

[12] Anonymous, "2009 AIDS epidemic update," UNAIDS. Geneva, 2009, http://www.unaids.org/en/dataanalysis/epidemiology/2009aidsepidemicupdate/.

[13] C. Ndondoki, F. Dabis, L. Namale et al., "Survival, clinical and biological outcomes of HIV-infected children treated by antiretroviral therapy in Africa: systematic review, 20042009," Presse Medicale, vol. 40, no. 7-8, pp. e338-e357, 2011.

[14] P. S. Sullivan, O. Hamouda, V. Delpech et al., "Reemergence of the HIV epidemic among men who have sex with men in north America, Western Europe, and Australia, 1996-2005," Annals of Epidemiology, vol. 19, no. 6, pp. 423-431, 2009.

[15] G. Likatavičius, I. Klavs, I. Devaux, J. Alix, and A. Nardone, "An increase in newly diagnosed HIV cases reported among men who have sex with men in Europe, 2000-6: implications for a European public health strategy," Sexually Transmitted Infections, vol. 84, no. 6, pp. 499-505, 2008.

[16] P. R. Gorry, C. Ong, J. Thorpe et al., "Astrocyte infection by HIV-1: mechanisms of restricted virus replication, and role in the pathogenesis of HIV-1-associated dementia," Current HIV Research, vol. 1, no. 4, pp. 463-473, 2003.

[17] I. P. Everall, L. A. Hansen, and E. Masliah, "The shifting patterns of HIV encephalitis neuropathology," Neurotoxicity Research, vol. 8, no. 1-2, pp. 51-61, 2005.

[18] S. Surendran, R. Matalon, and S. K. Tyring, "Upregulation of aspartoacylase activity in the duodenum of obesity induced diabetes mouse: implications on diabetic neuropathy," Biochemical and Biophysical Research Communications, vol. 345, no. 3, pp. 973-975, 2006.

[19] S. Surendran, "Upregulation of N-acetylaspartic acid alters inflammation, transcription and contractile associated protein levels in the stomach and smooth muscle contractility," Molecular Biology Reports, vol. 36, no. 1, pp. 201-206, 2009.

[20] A. Wiercińska-Drapało, E. Tarasów, and J. Jaroszewicz, “The central nervous system and HIV infection," Neurologia $i$ Neurochirurgia Polska, vol. 37, 2, pp. 15-19, 2003.

[21] K. Aoki-Yoshino, T. Uchihara, C. Duyckaerts, A. Nakamura, J. J. Hauw, and Y. Wakayama, "Enhanced expression of aquaporin 4 in human brain with inflammatory diseases," Acta Neuropathologica, vol. 110, no. 3, pp. 281-288, 2005.

[22] S. Surendran, L. S. Shihabuddin, J. Clarke et al., "Mouse neural progenitor cells differentiate into oligodendrocytes in the brain of a knockout mouse model of Canavan disease," Developmental Brain Research, vol. 153, no. 1, pp. 19-27, 2004.

[23] S. Surendran, S. K. Tyring, K. Michals-Matalon, and R. Matalon, "Therapeutic options in prevention and treatment of aspartoacylase gene mutation resulting abnormalities in Canavan disease," Current Pharmacogenomics, vol. 2, no. 1, pp. 13-20, 2004.

[24] J. E. Bell, "The neuropathology of adult HIV infection," Revue Neurologique, vol. 154, no. 12, pp. 816-829, 1998.

[25] M. A. Cosenza, M. L. Zhao, S. L. Shankar, B. ShafitZagardo, and S. C. Lee, "Up-regulation of MAP2e-expressing oligodendrocytes in the white matter of patients with HIV-1 encephalitis," Neuropathology and Applied Neurobiology, vol. 28, no. 6, pp. 480-488, 2002.

[26] K. D. Mack, X. Jin, S. Yu et al., "HIV insertions within and proximal to host cell genes are a common finding in tissues containing high levels of HIV DNA and macrophageassociated p24 antigen expression," Journal of Acquired Immune Deficiency Syndromes, vol. 33, no. 3, pp. 308-320, 2003. 


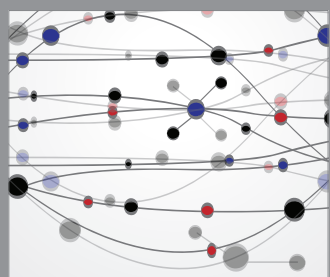

The Scientific World Journal
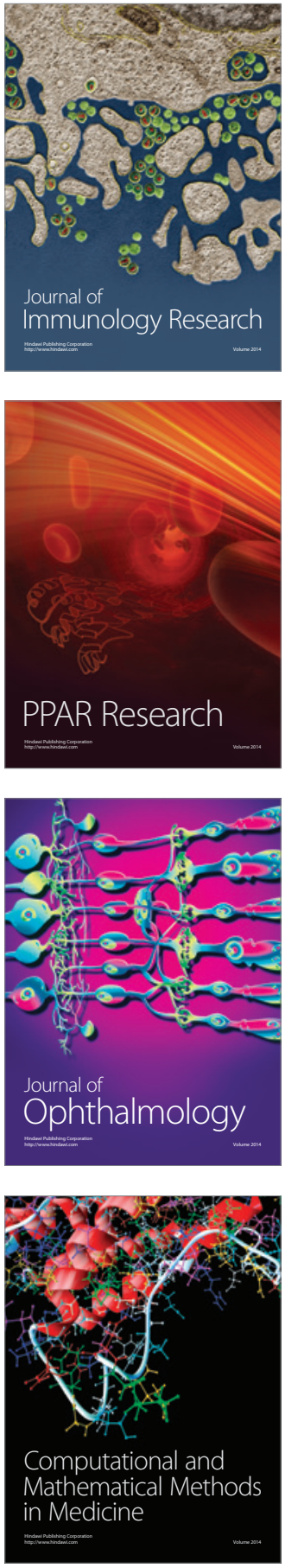

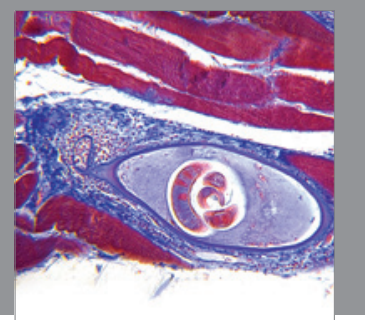

Gastroenterology

Research and Practice
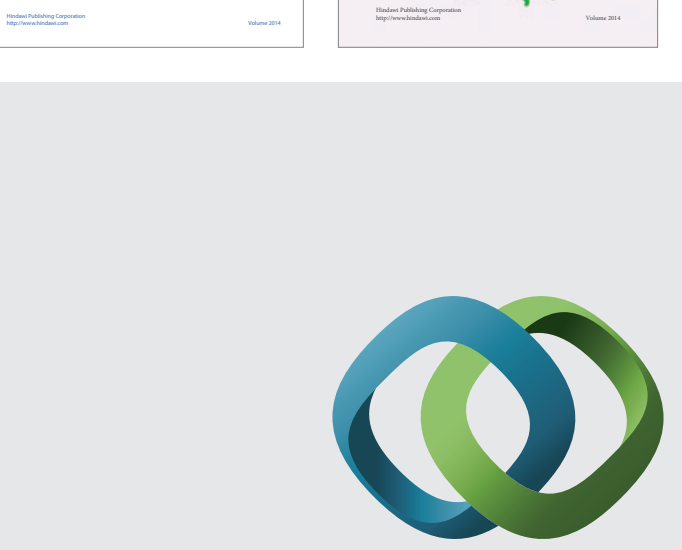

\section{Hindawi}

Submit your manuscripts at

http://www.hindawi.com
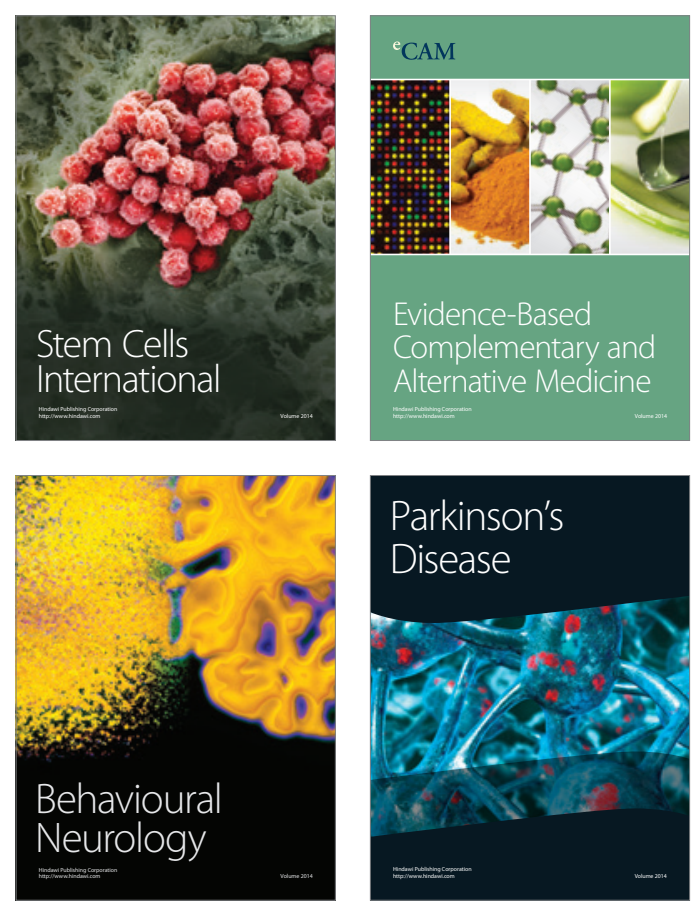

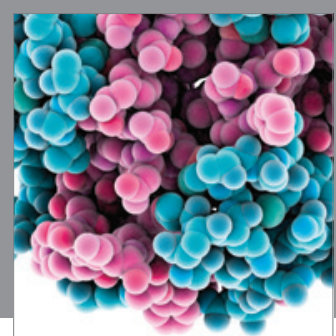

Journal of
Diabetes Research

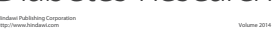

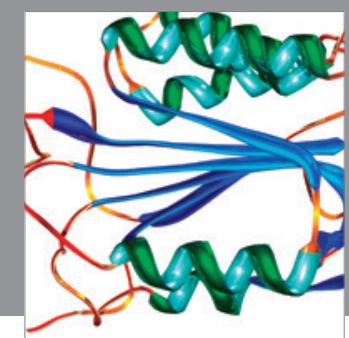

Disease Markers
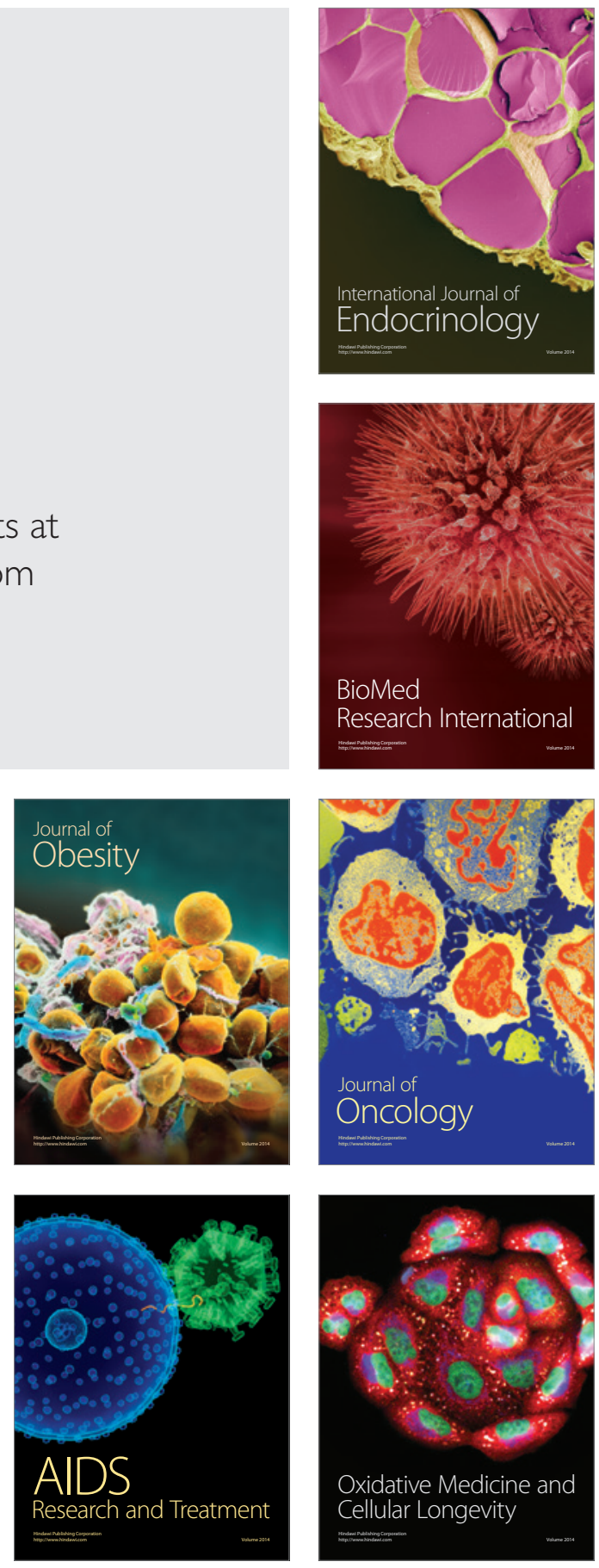